\title{
Implications for health education and intervention strategies arising from children's caregivers concerns following successful malaria control.
}

Maria (Riana) Bornman ${ }^{\mathrm{a} *}$, Lawrence Schlemmer ${ }^{\mathrm{b}}$, Tertia van der Walt ${ }^{\mathrm{b}}$, Cobus van Dyk $^{k^{* *}}$, Hindrik Bouwman ${ }^{\mathrm{c}}$.

\author{
Author names and affiliations: \\ ${ }^{a}$ Department of Urology and University of Pretoria Centre for Sustainable Malaria Control, University \\ of Pretoria, Private Bag X169, Pretoria 0001, South Africa \\ ${ }^{\mathrm{b}}$ MarkData (Pty) Ltd, 8, Marais Street, Bailey's Muckleneuk 0181, Pretoria, South Africa \\ ${ }^{\circ}$ School of Environmental Sciences and Development, North-West University, Private Bag X6001, \\ Potchefstroom 2520, South Africa
}

\section{* Corresponding author}

Tel: +27123541513

Fax: +27 123542500

Email address: riana.bornman@up.ac.za

** Current address: Centre for Aquatic Research, Department of Zoology, University of Johannesburg, Auckland Park, Johannesburg, South Africa.

Running title:

Caregivers concerns and successful malaria control

\section{Summary}

We investigated the interaction between social and economic circumstances with malaria awareness in rural South African villages effectively protected from malaria infection by community-passive, indoor residual spray (IRS) performed by government. We conducted interviews with 120 caregivers of children using both open-ended and closed fixed-answer questions. The mean income was between 27 and $56 \%$ of the national mean, indicating a community under considerable pressure. Male parents were often absent due to work commitments. Unemployment, poverty, crime, and clean water were the main, unprompted, threats, but malaria was volunteered by none. Only when malaria was prompted (caregivers had good knowledge of malaria), did its concern rise. Malaria, therefore, was not a prominent conscious concern. This implies that alternatives to IRS that require increased community and personal engagement, behavioural changes, and time commitment (such as certain components of integrated vector management and bed nets), will 
face implementation challenges. Unless community-passive malaria control measures can be developed that is as good or better than IRS, it seems unreasonable to expect poor communities to adopt community-active systems. Our findings should be considered in malaria control strategies, rural policy development, climate change adaptation, and communication strategies.

Keywords: Socio-economic conditions, malaria, indoor residual spraying, South Africa, DDT, climate change adaptation

\section{Introduction}

Control of malaria remains one of the world's greatest current public health challenges, particularly in sub-Saharan Africa. ${ }^{1}$ Malaria is still responsible for $10 \%$ of the total disease burden in Africa, ranked second after human immune deficiency virus/acquired immunodeficiency syndrome (HIVIAIDS ). ${ }^{2}$ In 2009, an estimated 236 million people contracted malaria globally, resulting in nearly 781000 deaths, of which $>90 \%$ were from Africa. In South Africa, 6072 people contracted malaria, and 45 died in $2009 .^{3}$

Initially, malaria was a disease of both tropical and temperate regions, but overall improvement in control, housing, nutrition and the success of the Global Malaria Eradication Campaign (1958-1969; World Health Organization (WHO)) all contributed significantly to interrupt malaria transmission in these regions. Tropical Africa was not included and also not targeted in subsequent efforts, ${ }^{1,4}$ despite the fact that ecological, vector, and climatic conditions particularly favour intense transmission and the vectors were highly responsive to indoor residual spraying (IRS) with insecticides (mainly dichlorodiphenyl-trichloroethane (DDT)). ${ }^{5}$ As a result, complete vector control was not achieved ${ }^{6}$ and international interest and funding for malaria research and control declined in most African countries. Today, malaria is regarded as a neglected tropical disease of poor countries ${ }^{2,4}$ including those in Africa. The recent increase in funding for malaria vector control will hopefully have a profound effect on health. ${ }^{3}$

The WHO World Malaria Report ${ }^{3}$ identified the four primary interventions necessary to respond effectively to malaria as a disease; the diagnosis of malaria cases and effective drug treatment, intermittent preventative treatment in infants, insecticidetreated nets (ITNs), and indoor residual spraying (IRS). IRS for malaria control, when conducted by government spray teams (as is the case for most African countries), is a highly effective, vertical intervention with little active community participation required compared with multi-sector (central or local government, together with communities) horizontal control programs such as Integrated Vector Management $(\mathrm{IVM})^{7}$ that was effective in Mexico and elsewhere. Sustainable preventive and community-active intervention strategies require that communities and local administrations in high-risk areas be very alert and responsive with respect to mosquito-borne infection. Such responsiveness presupposes adequate levels of risk 
awareness and active, sustained concern. ${ }^{8}$ However, the adoption of communityactive disease risk avoidance measures by communities themselves is often slow and uneven, ${ }^{9}$ which to some extent implies weak or inconsistent awareness or motivation. Assuming that malarial infection is an unambiguously serious and life threatening condition of which all or most people are aware, a reasonable assumption would be to expect 'rational' response to known risks. However, rational responses to demonstrated risk cannot be expected in all social and cultural settings. Deviations from a 'scientifically-based rationale' are often the reason why intervention programmes do not achieve the desired or expected outcomes. Specific risk-avoidance practices may be crowded-out by a welter of other exigencies such as a wider array of health risks, economic deprivation, and risks from perceived supernatural forces ${ }^{10}$. Furthermore, parents and household members in poor communities may become so demoralised by their conditions that they develop a defeatist attitude. ${ }^{11}$ In spite of the above, various studies have shown the important roles of mothers, guardians, and caregivers of children in prevention, early detection, and management of malaria. ${ }^{12,13}$

Caregivers are the most aware of the social and economic stress relating to the care of children. The general and daily care priorities of caregivers are not well understood, especially as they have to balance competing social, economic, and health imperatives. This investigation aimed to compare the relative importance assigned by female caregivers in communities under a successful verticallymanaged malaria control programme to malaria awareness on the one hand, and social and economic concerns on the other. Such insights are vital in the design and refinement of locally applicable health education and intervention strategies and programs to prevent malaria, as well as to help anticipate community needs and capacity if or when malaria spreads.

\section{Material and Methods}

\section{Study area description and population}

The Human Ethics Committee of the Faculty of Health Sciences, University of Pretoria (UP 49/2007), and the Department of Health and Social Development of the Limpopo Government (4/2/2 2007) approved the study. The malaria situation in Limpopo Province was discussed by Gerritsen et al. ${ }^{13}$ Briefly, between 1998 and 2007, altogether 58768 cases and 628 mortalities associated with malaria were reported. Annual case fatality rates never exceeded $1.8 \%$ of cases (in 2003-2004, equating to $0.0002 \%$ of the total population). The malaria control system here, as elsewhere in South Africa, ${ }^{14}$ combines intensive IRS (often with DDT), disease surveillance, free case management at hospitals and clinics, epidemic preparedness and response, and health promotion. ${ }^{15}$ The low malaria incidence indicates a very effective, government managed (vertical), malaria control system, with little input from communities required, other than disease symptom awareness and cooperation with IRS teams once a year. ${ }^{14}$ 
This descriptive cross-sectional study was conducted during April and May 2008 in the malaria-endemic Thulamela Local District, east of the city of Thohoyandou, Limpopo Province, South Africa, where annual DDT spraying occurs. The Limpopo Province is situated in the northeastern part of South Africa and is divided into six districts, one of which is the Vhembe District Municipality (VDM), and Thulamela is a Local District in Vhembe. The VDM has an estimated population of 1.1 million people with about 537000 (95\%) in the rural Thulamela area.

After consultation with the Regional Department of Health and Development, two study villages (V1 and $\mathrm{V} 2$ ) in the Thulamela Local District were selected as representative villages. The reference village $(R V)$ was in a non-malaria area outside the DDT-sprayed area. The basic lifestyles and cultural features of the sampled homesteads in the three villages were typical for this area; the mostly Tshivenda speaking people have comparable access to basic services such as schools, primary health care clinics, but many still collect wood and water. Most families live in round, thatch-roofed huts in compact homestead arrangements, sometimes interspersed with newer small Western-type brick houses. Formal employment opportunities are few, and many are subsistence farmers. ${ }^{16-18}$

Based on aerial photographs, random starting points for systematic homestead sampling were identified. Because the villages are informally planned and homesteads are often without clear site boundaries, it was impossible to derive a precise number of homesteads for each village. An interval-estimation was used to cover the entire settlement and yield the target samples sizes. The two malaria villages were of comparable size with about 600 homesteads each, and the reference village had 1700 homesteads. The sampling interval for the reference village was every 48th homestead, yielding 36 homesteads; for the two study villages it was every 10 th homestead, yielding 60 homesteads each. In each selected homestead, the adult with the main responsibility for the day-to-day care of the children (mother, relative, or guardian, defined here as caregiver) was approached for the interview. The selected homesteads were visited repeatedly if the caregiver was absent the first time; eventually, no homestead substitutions were necessary. This study sampled 156 homesteads; 60 each from V1 and V2, and 36 from the control village (RV).

\section{Questionnaire}

Two of the authors (LS and TvdW), with extensive experience in surveys and strategic research, compiled the questionnaire in collaboration with the team and supervised the survey. A draft questionnaire was pre-tested and improved in a pilot study using 16 randomly selected homesteads from another malaria village with comparable social conditions. This was done to assess the respondents' reactions, 
the appropriateness of the questions, and the suitability of format and wording of questions. The questionnaire included open-ended questions (Box 1) allowing for both unprompted and closed fixed-answer alternative (prompted) items (similar to cross-sectional approaches used by others. ${ }^{14,15}$ The questionnaire covered malaria and HIVIAIDS, socio-economic conditions, household challenges, and causes of concern including malaria. Face-to-face interviews with caregivers were then conducted by experienced interviewers that were recruited, trained, and briefed for this particular study.

Data analysis

Data were double-entered into Excel, checked for consistency, and then transferred to STATA for analysis. Answers to open- and closed-ended questions and further responses were coded for capturing and computer analysis. The dataset was analysed using cross-tabulation software (SPSS and MS Excel), as well as Prism (GraphPad Software, Inc).

\section{Results}

\section{Socio-economic conditions}

The socio-economic profiles are presented in Table 1. All respondents were female and functionally the primary caregivers of the children in each homestead. The key domestic responsibilities were childcare (health, nutrition, and education), as well as collecting water and firewood. The mean ages of respondents in the two malaria villages (V1 and V2) were 40 and 38 years respectively, with between 2-3 children (aged 0-16 years) per household. The reference village (RV), however, had slightly older respondents, but the difference between the three villages was not significant (ANOVA, $p>0.05$ ). Two relatively high income homesteads from $R V$ were excluded as these had resident salary earners, different from the other types of incomes (child grants and pensions) of the rest of the homesteads. The mean homestead income was $37 \%(\mathrm{~V} 1), 27 \%(\mathrm{~V} 2)$, and $56 \%$ of the national mean.

Adult residents were the main source of physical assistance with childcare (Table 1), but $>20 \%$ of caregivers had no assistance at all. The husband/father of the children physically assisted with childcare in $<15 \%$, but provided financial support in almost $40 \%$ of the homesteads. Consistently, between $22-25 \%$ of the caregivers were the sole income earners (Table 1).

Responding to a question in "How happy or not are you living in this area?" (the options were "very happy, fairly happy, not happy"), caregivers in V1 were generally happier than those in V2 and RV, but almost all caregivers (89.2\%) appeared to be highly satisfied with their community settings ("very happy"). In the two malaria villages $17 \%$ and $14 \%$ respectively of respondents older than 20 years have grade 12 or higher education, compared to $20 \%$ among Black South Africans in $2007 .^{19}$ 


\section{Household challenges and causes of concern}

Interviews commenced with a general question on problems and dangers causing persistent anxiety. The question was non-directive and open-ended, requiring volunteered, unprompted replies (Table 2). Overall, more than two-thirds of respondents had such concerns and many worried a great deal $(52 \%, 48 \%$, and $39 \%$, respectively; data not shown). The key volunteered issues of concern are listed in Table 2. More than $50 \%$ of respondents were most concerned about unemployment and poverty, but crime, worries about the safety of children under their care, schooling expenses, and housing were also prominent. Up to $20 \%$ mentioned concerns about their own health, but malaria was volunteered by none. Some $17 \%, 18 \%$ and $8 \%$ of caregivers in the respective villages said that one or more members of the household had had malaria at some stage in the past. The majority of respondents in the two malaria villages correctly associated malaria with mosquitoes and mosquito bites ( $86 \%$ and $93 \%$, respectively). The remainder attributed the disease to other causes, all connected with dirty or stagnant water, but not with mosquitoes.

Table 2 also summarizes the volunteered, unprompted responses to an open-ended question on how much malaria and mosquito bites worried them. Except for one caregiver in V2, none of the respondents suggested malaria as a cause for concern. When the respondents were asked to identify (unprompted) specific health threats to children, malaria as well as mosquito bites were volunteered by $\leq 15 \%$ of the respondents. Malaria, therefore, was not a significant or prominent conscious component of the set of concerns of caregivers in any village.

Prompted questions on child health threats however, elevated malaria concern to $\geq 38 \%$ in the malaria villages and as a prompted illness most feared to more than $33 \%$. It was only when asked what diseases worry them a great deal from a fixed response item list, that the malaria related responses became substantial $(73 \%$, $52 \%$, and $50 \%$, respectively). The proportions of respondents choosing the fixed response very serious to the threat of malaria to their children's health and welfare were even higher, namely $87 \%, 77 \%$, and $69 \%$, respectively. Mosquito bites elicited a high level of respondents expressing a great deal of worry, namely $82 \%, 63 \%$ and $42 \%$, respectively.

Caregivers were also interviewed about their major sources of emotional comfort in their role as caregivers. The importance of children's health certainly came to the fore, and was on the same level as religion (Table 2). Welfare and child social grants were regarded by $37 \%, 27 \%$, and $19 \%$, respectively, as a source of comfort. 


\section{Discussion}

The results showed a community under considerable economic pressure household income levels were between $27 \%$ and $56 \%$ of the South African mean, comparable with a similar study ${ }^{15}$ from Mpumalanga, another endemic malaria province, in South Africa. Despite the low cost of traditional housing, the cost of living is often higher in remote rural areas as there is less access to chain stores with lower priced commodities. Another severe economic constraint is the taxing burden of childcare in the absence of male partners of the caregivers due to migrant labour. There was also far more community and own family support for caregivers than support from the male parents, although many of the absent fathers of children provided some financial assistance in meeting domestic and child raising costs. Other than a slightly higher educational level and two high-income residents in RV, there were no other obvious or measured socio-economic differences between the caregivers of the different villages and the villages in Mpumalanga Province covered by Govere et al. ${ }^{14}$ and Castillo-Riquelme et al. ${ }^{15}$ The assessment by caregivers as to the quality of their community circumstances, however, contrasted markedly with their economic condition as the vast majority of respondents in all villages expressed happiness with their community life and location. The apparent contradiction of acceptable community circumstances with a heavy economic burden needs to be kept in mind when investigating the malaria-related concerns of caregivers.

Given the living conditions outlined above, the responses to questions on persistent worries, concerns, and threats to their health and welfare were not obviously interpretable. For example, in their volunteered (unprompted) replies to open-ended questions about worries and concerns, issues related to poverty, unemployment, crime, schooling expenses, housing, and the lack of fresh water dominated their everyday consciousness. In contrast, a modest proportion worried about childcare and expressed concerns about their own health; caregivers did not volunteer children's health issues at all. There was also a very low level of volunteering diseases in general and no mention of malaria at all. Hence, their unprompted, everyday awareness of pressures and risks did not encompass the potentially serious disease threats that they and their children face on a day-to-day basis. The lack of unprompted reference to malaria could not be due to lack of awareness of this disease as $\sim 18 \%$ of households had been directly affected by malaria in the past, and by their very good knowledge that malaria is caused by mosquitoes ( 86 to $93 \%$ ). This is quite a high percentage when compared with some studies from Africa (taking into account different target groups, methodologies, and questionnaire design $)^{20,21}$, and surely sufficient to maintain the malarial threat in caregivers' minds

There was more uncertainty in the more focused probes into health threats, Although malaria was not spontaneously volunteered as a cause of concern, it was recognised as a dominant threat when prompted. While a mosquito bite or potential malaria will be understood to be life-threatening, in our study and possibly in other parts of 
Africa, it does not compete on a day-to-day basis with the constant frustrations or fears associated with poverty, unemployment, or crime, even when the general quality of life seems to be acceptable, combined with a low incidence of malaria. Hence, it is only when the caregiver was prompted about malaria that the underlying anxiety was brought to the conscious level. We are not aware of studies comparing economic and disease conditions with perceptions regarding malaria. Neither have many studies been done under successful, community-passive, malaria control conditions using IRS. What is obvious, however, is the central and important role that women as caregivers of children play.

The only protection against malaria these communities have are vertical, communitypassive IRS, and associated support structures such as clinics and free treatment for malaria. Given the current low incidence of malaria in this region, this system seems stable and very effective. Changes in policy towards more community-active measures such as shifting from IRS to insecticide treated nets (ITNs) may therefore be counterproductive in settings such as we investigated. Poor communities are dependent on vertical control measures, at least until economic improvement and other initiatives allows gradual transfer of responsibility to communities and eventually to individuals. The dialectic regarding ITNs and IRS in southern Africa has recently been summarised by Cliff et al. ${ }^{22}$ as these two methods are currently the principal strategies recommended for vector management. ${ }^{23}$ Both seemed equally effective, costs were similar ${ }^{24}$ and each one has a place in integrated malaria vector management.

We have shown that caregivers under a successful vertical control system have significant knowledge and awareness of malaria but also that malaria did not dominate their everyday concerns. The reason(s) for the dichotomy in the risk awareness of malaria is not obvious but it will significantly increase the difficulty in mobilising communities for preventive action. Current malaria prevention in South Africa can be seen as an effective control system without the need for any serious behavioural changes or practices that seem to impose significantly on daily, overriding socio-economic concerns and anxieties. The dichotomy has a further implication that alternative means of malaria control such as Integrated Vector Management (IVM) and wide-scale use of ITNs, which requires far more community and personal engagement, behavioural changes, awareness, and time commitment compared with an IRS system, will face implementation challenges, possibly on a greater scale than prevention of HIVIAIDS, as it concerns all members of society acting against mosquito vectors for most of the year. Where men are often absent from home due to work opportunities in distant centres and mothers (or others) then act as caregivers of families, even less time and resources would be available to service the required actions inherent in community-based control programmes. Given the current success of IRS and associated support systems in malaria prevention in Limpopo ${ }^{13}$ and elsewhere, unless other community-passive and 
successful methods for the prevention of malaria transmission can be developed (such as house screening or house design modifications) ${ }^{25,26}$ that is as good or better than IRS, it seems unreasonable to expect poor communities to adopt a far more community-active system while they are still battling with poverty and other overriding day-to-day issues.

In poor communities, introduction of community-active malaria control could add to economic and social stress, not relieve it Exposure to IRS insecticides may have human and environmental health impacts. ${ }^{17-19}$ Therefore, one should be aware of the possibility that the lack of community involvement in an existing community-passive malaria control system may also become a problem when promoting measures to reduce exposure to IRS chemicals ${ }^{27}$, as some of these are likely to involve behavioural changes.

Our results point out the important role of caregivers in rural communities. This function seems to be performed very effectively with minimal means and a surprising amount of 'happiness'. Any changes to this system will therefore have to take exceptional care not to impact on this effectiveness other than to improve it. Considerations should be given to study the needs requirements of the caregiver as a crucial component of rural community life as it seems to have adapted to recent social and economic changes.

Our results may also indicate that the selection of either community-passive or active forms of malaria control in areas where it has been previously eliminated, or the appearance of malaria in new areas (possibly due to climate change), ${ }^{28,29}$ need to take account of social and economic considerations. Malaria, poverty, and economic development go hand in hand. ${ }^{4}$ Therefore, a centralized, communitypassive, malaria control system (such as IRS with associated support mechanisms) may afford poor communities with a more reliable buffer of safety from climate change ${ }^{30}$ and perhaps also from economic upheavals. This also implies that until such time that an effective alternative to DDT is freely available, all possible preventative measures must be taken by both spray-workers and residents to limit any unwarranted exposures. Our findings should therefore be considered during malaria control and rural economic policy development and reviews, climate change adaptation, and communication, education and implementation strategies.

\section{Authors' contributions}

$\mathrm{MB}, \mathrm{LS}$, TvdW and CvD designed the study protocol and oversaw implementation of the study; MB, LS and TvdW developed the analysis plan; MB, LS, TvdW and HB analysed and interpreted the data and drafted the report. All authors read, revised and approved the final manuscript. MB, TvdW and HB are guarantors of the paper. 


\section{Acknowledgements}

We thank Mrr P Kruger and R Mudzielwana (Malaria Control Programme, Limpopo Province) for assistance in approaching the communities. The comments from two reviewers were very helpful in improving the manuscript and they are thanked. The authors' immense gratitude goes to the caregivers who participated in the study.

\section{Funding}

We received financial support from the National Research Foundation (NRF) of South Africa and the Post-doctoral Programme of the University of Pretoria.

\section{Conflicts of interest}

None declared.

\section{Ethical clearance}

The Human Ethics Committee of the Faculty of Health Sciences, University of Pretoria (UP 49/2007), and the Department of Health and Social Development of the Limpopo Government (4/2/2 2007) approved the study.

\section{References}

1. Musawenkosi LH, Mabaso LH, Sharp B, Lengeler C. Historical review of malarial control in southern Africa with emphasis on the use of indoor residual house-spraying. Trop Med Int Health 2004; 9:846-856.

2. Lopez AD, Mathers CD, Ezzati M, Jamison DT, Christopher J L Murray CJL. Global and regional burden of disease and risk factors, 2001: systematic analysis of population health data. Lancet 2006; 367:1747-57.

3. World Malaria report WHO. 2010. World Health Organization, World Malaria Report. Global Malaria Programme. Geneva. Available at: http://www.who.int/malaria/world malaria report 2010/en/index.html. [Accessed 7 June 2011].

4. Teklehaimanot A, Mejia PM. Malaria and poverty. Ann NY Acad Sci 2008; 1136:32-37.

5. De Meillon B. 1936. The control of malaria in South Africa by measures directed against adult mosquitoes in habitations. Quarterly Bulletin of the Health Organization of the League of Nations 1936; 5:134-137.

6. Nájera JA. Malaria control: achievements, problems and strategies. Parassitologia 2001; 43:1-89.

7. Van den Berg $\mathrm{H}$. Global status of DDT and its alternatives for use in vector control to prevent disease. Environ Health Perspect 2009;117:1656-1663.

8. Nieto T, Mendez F, Carrasquilla G. Knowledge, beliefs and practices relevant for malaria control in an endemic urban area of the Columbian Pacific. Soc Sci Med 1999; 49:601-609.

9. Rashed S, Johnson H, Dongier P, Moreau R, Lee, Schaffer C. Determinants of the Permethrin Impregnated Bednets (PIB) in the Republic of Benin: the role of women in the acquisition and utilization of PIB. Soc Sci \& Med 1999; 49:993-1005. 
10. Comoro C, Nsimba SED, Warsame M, Tomson G. Local understanding, perceptions and reported practices of mothers/guardians and health workers on childhood malaria in a Tanzanian district - implications for malaria control. Acta Tropica 2003; 87: 305-313.

11. Witte K. Putting the fear back into fear appeals: The extended parallel process model. Communic Monogr 1992; 59:329-349.

12. Kidane G, Morrow RH. Teaching mothers to provide home treatment of malaria in Tigray, Ethiopia: a randomised trial. Lancet 2000; 356:550-555.

13. Gerritsen AM, Kruger P, Schim MF, van der Loeff MF, Grobush MP. Malaria incidence in Limpopo Province, South Africa, 1998-2007. Malaria J 2008; 7:162.

14. Govere J, Durrheim D, la Grange K, Mabuza A, Booman M. Community knowledge and perceptions about malaria and practices influencing malaria control in Mpumalanga Province, South Africa. S Afr Med J 2000; 90:611-616.

15. Castillo-Riquelme M, Mclntyre D, Barnes K. Household burden of malaria in South Africa and Mozambique: is there a catastrophic impact? Trop Med Int Hyg 2008;13:108-122.

16. Van Dyk JC, Bouwman H, Barnhoorn IEJ, Bornman MS. DDT contamination from indoor residual spraying for malaria control. Science Total Environment 2010; 408:2745-2752.

17. Aneck-Hahn NH, Schulenburg GW, Bornman MS, Farias P, de Jager C. Impaired semen quality associated with environmental DDT exposure in young men living in a malaria area in the Limpopo Province, South Africa. $J$ Androl 2007; 28:423-434.

18. Bornman R, de Jager C, Worku Z, Farias P, Reif S (2010). DDT and urogenital malformations in newborn boys in a malarial area. BJU Int 2010; 106:405-11.

19.Statistics South Africa. Population census, 2001. Available at: http://www.statssa.gov.za/publications/SAStatistics/SAStatistics2007.pdf. [Accessed 7 June 2011].

20. Tarimo DS, Urassa DP, Msamanga GI. Caretakers' perceptions of clinical manifestations of childhood malaria in holo-endemic rural communities in Tanzania. East Afr Med J 1998; 75:93-96.

21. Masendu HT, Sharp BL, Appleton CC, Chandiwana SK, Chitono C. Community perception of mosquitoes, malaria and its control in Binga and Gokwe districts, Zimbabwe. Cent Afr J Med 1997; 43 :71-75.

22. Cliff J, Lewin S, Woelk G, Fernandes B, Mariano et al. Policy development in malaria vector management in Mozambique, South Africa and Zimbabwe. Health Policy Plan 2010 doi: 10.1093/heapol/czq008.

23. Morel CM, Lauer JA, Evans DB. Cost effectiveness analysis of strategies to combat malaria in developing countries. BMJ 2005; doi:10.1136/bmj.38639.702384.AE (published 10 November 2005).

24. Lengeler C, Sharp V. Indoor Residual Spraying and Insecticide-Treated Nets. In: Reducing Malaria's Burden. Evidence of Effectiveness for Decision Makers. Washington DC: Global Health Council 2003;17-24.

25. Coleman M, Coleman M, Mabaso MLH, Mabuza AM, Kok G, et al. Household and microeconomic factors associated with malaria in Mpumalanga, South Africa. Trans R Soc Trop Med Hyg 2010; 104:143-147. 
26. Kirby MJ, Ameh D, Bottomley C, Green C, Jawara M, et al. Effect of different house screening interventions on exposure to malaria vectors and on anaemia in children in The Gambia: a randomised controlled trail. The Lancet 2009; 374: 998-1009.

27. Bouwman $\mathrm{H}$, van den Berg, $\mathrm{H}$, Kylin $\mathrm{H}$. DDT and malaria prevention: Addressing the paradox. Env Health Perspect 2011; 119:744-747.

28. Gething PW, Smith DL, Patil AP, Tatem AJ, Snow RW, et al. Climate change and the global malaria recession. Nature 2010; 465: 342-345.

29. Parham PE, Michael E. Modelling the effects of weather and climate change on malaria transmission. Env Health Perspect 2010; 118:620-626.

30. Wandinga SO, Opondo M, Olago D, Githeko A, Githui F, et al. Vulnerability to epidemic malaria in the highlands of Lake Victoria basin: the role of climate change/ variability, hydrology and socio-economic factors. Climatic Change 2010; 99:473-497. 
Box 1: Some of the open-ended questions

Malaria

- How critically aware are people of malaria as a serious and possibly life-threatening ailment?

- Consequently, to what extent do they perceive spraying of a mosquito poison as necessary?

- Do they think that the interruptions to domestic routines are warranted?

- What constructions do they put on the motivations of the authorities that conduct the spraying?

- To what extent are the risks of both malarial infection and DDT contamination accepted as serious or inevitable?

- Do they roughly understand the cause-effect relationships?

Daily or regular risks

- To what other daily or regular risks are the people and their children in the communities exposed?

- What worries you most?

- What are the biggest dangers or problems facing the children?

- How would the risk of malarial infection and the risk of contamination compare in their mindsets to the other threats and risks that they face?

- What are the biggest threats to their health?

- What diseases or ailments are the most serious threats to children growing up in an area like this?

- What illnesses do you fear most over the next few years?

- How happy or not are you living in this area? Very happy, fairly happy or not happy.

- What things make you unhappy?

Alternative or popular explanations

- Do many of the people not perhaps have alternative or popular explanations for the consequences that can occur?

- Are these consequences not perhaps seen, or partly seen, as due to forces other than disease or contamination - supernatural forces, witches, other pathologies, the moral consequences of behaviour or the hostile intentions of neighbours and local enemies?

Regular and routine behaviour in the households

- Aside from regular and routine behaviour in the households, what are the typical patterns of reaction to safety instructions and other expectations conveyed to residents?

- A not uncommon reaction in modern middle class communities, for example, is for parents to worry about their children, to worry about disease, to worry about debt, etc. etc., but people in a particular socio-economic culture may have a far less obsessive mindset and be far more passive or perhaps so tired and harassed that they leave consequences to fate. 
Table 1 - Socio-economic profiles of the caregivers of the three villages

\begin{tabular}{|c|c|c|c|}
\hline & $\begin{array}{l}\mathrm{V} 1 \\
\mathrm{n}=60\end{array}$ & $\begin{array}{l}\mathrm{V} 2 \\
\mathrm{n}=60\end{array}$ & $\begin{array}{l}\mathrm{RV} \\
\mathrm{n}=36\end{array}$ \\
\hline Mean age of respondents (years) ${ }^{a}$ & 40.4 & 37.8 & 44.9 \\
\hline Median & 39.5 & 36.0 & 38.0 \\
\hline Min - Max & $21-70$ & $17-70$ & $21-86$ \\
\hline Lower / upper $95 \% \mathrm{Cl}$ & $37 / 43$ & $35 / 41$ & $39-51$ \\
\hline Mean number of children in care ${ }^{a}$ & 2.8 & 2.3 & 2.4 \\
\hline Median & 3 & 2 & 2 \\
\hline Min - Max & $1-8$ & $1-5$ & $1-5$ \\
\hline Lower / upper $95 \% \mathrm{Cl}$ & $2.5 / 3.1$ & $2.1 / 2.6$ & $2.0 / 2.8$ \\
\hline \multicolumn{4}{|l|}{ Finances (Rands) } \\
\hline Mean monthly income available to caregiver ${ }^{a}$ & $2269^{b}$ & 1659 & 2298 \\
\hline Median & 1810 & 1358 & 1625 \\
\hline Min - Max & $100-11500$ & $190-6600$ & $630-7500$ \\
\hline Lower / upper $95 \% \mathrm{Cl}$ & $1786 / 2751$ & $\begin{array}{l}1308 / \\
2010\end{array}$ & $\begin{array}{l}1783 / \\
2764\end{array}$ \\
\hline Very happy in community (\%) & 97 & 82 & 81 \\
\hline Source of financial assistance & $\%$ & $\%$ & $\%$ \\
\hline Caregiver only & 22 & 22 & 25 \\
\hline Caregiver and husband/father of children & 55 & 47 & 39 \\
\hline $\begin{array}{l}\text { Caregiver, family members, neighbours, } \\
\text { friends }\end{array}$ & 23 & 31 & 36 \\
\hline Physical assistance to caregivers & $\%$ & $\%$ & $\%$ \\
\hline None - caregiver only & 23 & 22 & 25 \\
\hline Assistance from others & 77 & 78 & 75 \\
\hline Education & $\%$ & $\%$ & $\%$ \\
\hline Grade 5 education or lower & 25 & 28 & 22 \\
\hline Grade 12 education or higher & 17 & 14 & 25 \\
\hline
\end{tabular}

Table 1 legend text.

${ }^{a}$ Not significantly different between villages; $p<0.05$; ANOVA; two high-income outliers (R20 000 and R23 000) removed from RV; number of children and income data were log transformed.

${ }^{\mathrm{b}} \mathrm{R} 1 \approx$ USD 0.13 
Table 2 - Causes of persistent concerns, and malaria-related responses

\begin{tabular}{|c|c|c|c|}
\hline Persistent sources of anxiety (prompted) & $\begin{array}{l}\text { V1 } \\
\%\end{array}$ & $\begin{array}{l}\text { V2 } \\
\%\end{array}$ & $\begin{array}{l}\text { RV } \\
\%\end{array}$ \\
\hline Poverty & 53 & 55 & 56 \\
\hline Unemployment & 55 & 50 & 52 \\
\hline Crime in the area & 37 & 30 & 28 \\
\hline Worries about children and orphans under care & 18 & 29 & 36 \\
\hline School expenses & 27 & 28 & 12 \\
\hline Adequacy and/or condition of housing & 25 & 13 & 24 \\
\hline Lack of clean, fresh, water & 23 & 8 & 16 \\
\hline Own health concerns & 10 & 13 & 20 \\
\hline \multicolumn{4}{|l|}{ Malaria related responses (unprompted) } \\
\hline Malaria & 0 & 0 & 0 \\
\hline Mosquitoes & 0 & 1.7 & 0 \\
\hline \multicolumn{4}{|l|}{ Biggest health threats to children (unprompted) } \\
\hline Malaria & 15 & 13 & 6 \\
\hline Mosquito bites & 0 & 3.3 & 2.8 \\
\hline \multicolumn{4}{|c|}{ Malaria as unprompted disease affecting members of the household in recent years } \\
\hline \multirow{2}{*}{\multicolumn{4}{|c|}{ Malaria as prompted disease at any time in the past affecting household members }} \\
\hline & & & \\
\hline & 17 & 18 & 8 \\
\hline \multicolumn{4}{|l|}{ What causes malaria? } \\
\hline Mosquito and mosquito bites & 86 & 93 & 0 \\
\hline \multicolumn{4}{|l|}{ Biggest health threats to children (prompted) } \\
\hline Malaria & 52 & 38 & 8 \\
\hline Mosquito bites & 0 & 0 & 0 \\
\hline \multicolumn{4}{|l|}{ Disease most feared (prompted) } \\
\hline Malaria & 48 & 33 & 6 \\
\hline \multicolumn{4}{|c|}{ How much do the following problems worry you? (prompted) } \\
\hline \multicolumn{4}{|c|}{ Malaria } \\
\hline A great deal & 73 & 52 & 50 \\
\hline From time to time & 3 & 6 & 0 \\
\hline A little & 10 & 15 & 11 \\
\hline Not at all & 13 & 25 & 39 \\
\hline \multicolumn{4}{|l|}{ Mosquito Bites } \\
\hline A great deal & 82 & 63 & 42 \\
\hline From time to time & 7 & 8 & 3 \\
\hline A little & 2 & 15 & 19 \\
\hline & 10 & 13 & 36 \\
\hline \multicolumn{4}{|c|}{$\begin{array}{l}\text { How serious do you think the following threat is to the health and welfare of the } \\
\text { children? }\end{array}$} \\
\hline \multicolumn{4}{|c|}{\begin{tabular}{|l|l|l|} 
Malaria & & \\
\end{tabular}} \\
\hline Very serious & 87 & 77 & 69 \\
\hline Fairly serious & 0 & 3 & 3 \\
\hline \multicolumn{4}{|l|}{ Source of comfort } \\
\hline Children's health and welfare & 47 & 52 & 58 \\
\hline Religion & 52 & 52 & 33 \\
\hline Welfare and child grants & 37 & 27 & 19 \\
\hline
\end{tabular}

